\title{
Interfaces entre políticas relacionadas a estratégias para redução de riscos de desastres: recursos hídricos, proteção e defesa civil e saneamento
}

Policies' interfaces related to disaster risk reduction strategies: water resources, civil protection and defense and sanitation

\section{Vinicius Ferreira Dulac Masato Kobiyama}

Submetido em: 14/09/17 Revisado em: 18/12/17 Aprovado em: 22/12/17
RESUMO: O objetivo do presente artigo foi, com base na metodologia de EIRD/ONU, analisar as características de três Políticas (Política Nacional de Recursos Hídricos, Política Nacional de Proteção e Defesa Civil e Lei de Diretrizes Nacionais para o Saneamento Básico) e suas interfaces com relação a estratégias para redução dos riscos de desastres. A análise mostra a existência de planos e estudos setoriais para o desenvolvimento de objetivos comuns. Além disso, mostra a necessidade de um nível mais elevado de compartilhamento das agendas dos órgãos responsáveis para implementação destes planos no contexto da intersetorialidade.

PALAVRAS-CHAVE: PNRH; PNPDEC; LDNSB; intersetorialidade; EIRD/ONU; risco de desastre
ABSTRACT: The objective of the present paper was based on the UNISDR methodology to analyze characteristics of three Policies (National Policy of Water Resources, National Policy of Civil Protection and Defense, and Law of National Directives for Basic Sanitation) and their interfaces concerning strategies for reducing the disaster risk The analysis demonstrated the existence of sectors' plans and studies for the development of common objectives. However, for the implementation of these plans in the intersectoriality context, it is necessary to develop a higher level to share the public policies' agendas.

KEYWORDS: National Policy of Water Resources; National Policy of Civil Protection and Defense; National Law of Basic Sanitation; Intersectoriality; UNISDR; Disaster Risk

\section{INTRODUÇÃO}

O International Hydrological Programme (IHP) da UNESCO encontra-se em sua oitava fase com o título: "Water Security: Responses to Local, Regional, and Global Challenges", tendo uma duração 8 anos (2014-2021). Sua agenda possui ênfase em gestão dos recursos hídricos, aspectos sociais e abordagem sistêmica e holística (JIMENEZ-CISNEROS, 2015).

De forma similar, a agenda de pesquisa da International Association of Hydrological Sciences (IAHS) para a década 2013-2022, intitulada "Panta Rhei Everything Flows: Change in hydrology and society" possui um enfoque interdisciplinar entre socioeconomia e geociências com o propósito de entender como os sistemas hidrológico e social interagem e evoluem sob a influência de fatores também em constante mudança (SAVENIJE, 2015). Essa década enfatiza a importância da sociohidrologia.

O Programa de Gestão de Riscos e Resposta a Desastres do Plano Plurianual 2012-2015 do Governo Federal (BRASIL, 2012a) demonstra a ocorrência de 
aumento exponencial dos recursos financeiros destinados em resposta aos desastres e para reconstrução no período de 2004 a 2010, de R 130 milhóes para $\mathrm{R} \$ 3$ bilhóes. Diversos fatores explicam esse aumento, desde o aumento da frequência e da intensidade dos fenômenos climáticos até a expansão e adensamento urbanos nas áreas sujeitas a inundaçóes, enxurradas e deslizamentos, a degradaçáo dos serviços ecossistêmicos, a pobreza, bem como uma inadequada percepçáo de risco por parte da sociedade e dos tomadores de decisão (BRASIL, 2012a; JIMENEZ-CISNEROS, 2015).

Embora tenha sido predominante o enfoque na resposta aos desastres, na última década do século XX observa-se uma evolução para uma abordagem mais integrada dos eixos que consideram fundamental o conhecimento de riscos, bem como as açóes prospectivas e corretivas para redução desses, e a preparação para o manejo dos desastres. O Programa 2040 "Gestão de Riscos e de Desastres", constante no Plano Plurianual (PPA) da União (Brasil, 2012) é considerado uma iniciativa central para a incorporação da temática de gestão de riscos de desastres (GRD) às agendas do planejamento urbano e da gestáo pública, pois introduz, pela primeira vez, a gestão de riscos de desastres ao orçamento da União, em sua concepçáo mais integrada, sob responsabilidade de diversos Ministérios do Governo Federal (NOGUEIRA et al., 2014).

Outra iniciativa mencionada por Nogueira et al. (2014) é a Lei 12.608/2012 que institui a Política Nacional de Proteção e Defesa Civil (PNPDEC) (BRASIL, 2012b). A PNPDEC, que tem dentre seus objetivos reduzir os riscos de desastres, dispóe sobre as competências compartilhadas e a necessidade de atuaçóes articuladas entre os entes federados e demais políticas setoriais.

Neste sentido, Jimenez-Cisneros (2015) nos mostra que é necessária uma maior compreensão sobre as causas dos desastres naturais (no contexto das incertezas associadas a sua ocorrência), bem como a melhoria da gestáo dos riscos e das crises a partir do desenvolvimento das políticas nacionais. Sendo este o objetivo fundamental do Tema 1 - Desastres relacionados à água e alteraçôes hidrológicas na oitava fase do IHP.
Dentre as diversas Políticas que influenciam e são influenciadas por questóes relacionadas aos riscos de desastres naturais, destaca-se: Recursos Hídricos, Saneamento Básico, Agricultura, Habitação, Energia, Meio Ambiente, Assistência Social, Educação e Saúde. No Brasil, Vendruscolo e Kobiyama (2007) identificaram as interfaces entre a Política Nacional de Recursos Hídricos (PNRH) e Política Nacional de Defesa Civil, com base em seus diplomas legais e a respectiva implementação de sistemas de gestão e instrumentos, relacionados aos desastres hidrológicos. Os autores demonstraram que se ambas as Políticas compatibilizarem esforços na prevenção dos efeitos dos desastres hidrológicos, pode-se otimizar açóes e até suprir a carência de recursos.

Assumpção et al. (2017) abordaram a possibilidade de integração entre as PNRH, PNPDEC, a Política Federal de Saneamento Básico e outras Políticas Públicas tais como do uso, parcelamento e ocupação do solo - Estatuto da Cidade (BRASIL, 2001), as quais podem contribuir para implementar ou melhorar o sistema de drenagem e para minimizar os desastres provocados por chuvas intensas e recorrentes. Assim, ressalte-se que Assumpção et al. (2017) analisaram com mais ênfase questôes relativas à inundação, bem como aspectos da interface da política de desenvolvimento urbano com as demais, ampliando o escopo da análise.

Deste modo, é necessário avançar as pesquisas na área de gestão de riscos de desastres hidrológicos a partir do estudo das interfaces entre as Política de Recursos Hídricos, Proteção e Defesa Civil e Saneamento. No momento da pesquisa de Vendruscolo e Kobiyama (2007), não existia a Lei 12.608/2012 (BRASIL, 2012b). Portanto, essa Lei deve ser analisada e, deve-se incluir na análise, a Política de Saneamento devido ao fato de que a mesma abrange elementos para definição de estratégias de redução de riscos e desastres, tais como: gestão integrada, participação social, segurança hídrica, dentre outros aspectos.

Assim, o objetivo do presente artigo foi analisar as características históricas do desenvolvimento das três referidas Políticas e suas interfaces com relação à abordagem de um assunto comum que as permeia: questôes relativas a água e estratégias para redução dos riscos de desastres. 
Portanto, no presente artigo optou-se por desenvolver uma pesquisa junto a três Políticas: PNRH, PNPDEC, e a Lei de Diretrizes Nacionais para o Saneamento Básico/Política Federal de Saneamento Básico (LDNSB/PFSB). Em nível nacional, elas possuem como marcos legais, respectivamente a Lei no 9.433/1997 (BRASIL, 1997), Lei no 12.608/2012 (BRASIL, 2012b) e a Lei no $11.445 / 2007$ (BRASIL, 2007).

Ressalte-se que a Lei no $11.445 / 2007$ não constitui a política nacional de saneamento básico; ela consiste na lei federal e estabelece diretrizes nacionais para o saneamento básico. Assim, a sua tradução em agenda pública está condicionada à capacidade de gestáo dos titulares dos serviços e do papel da União para fazer com que seja implementada com aderência a esses princípios (SNSA/MIC, 2014).

Foram efetuadas análises sobre o histórico do processo de implementação de cada Política, com ênfase em dois aspectos: i) Análise do marco da criação da Política, ou seja, o evento ou ambiente que influenciou o início dos movimentos com vistas à sua implementação, e; ii) Identificação dos atores sociais (órgãos públicos, sociedade civil e agentes privados) que fizeram e que fazem parte do processo de implementação da Política. Ainda, foram efetuadas análises junto aos documentos oficiais (ex: diplomas legais, planos e estudos), em que observou-se como a intersetorialidade se expressa em cada Política.

\section{CARACTERÍSTICAS DAS TRÊS POLÍTICAS}

\section{Política de Recursos Hídricos}

A Constituição Federal de 1988 (CF/88) (BRASIL, 1988) definiu as condiçôes de dominialidade dos cursos de água (federal ou estadual) bem como a previsão de que a União e os Estados devem instituir suas respectivas Políticas e Sistemas de Recursos Hídricos. A PNRH instituída pela Lei no 9.433/1997 (BRASIL, 1997) contempla, dentre outros aspectos, o arranjo institucional para implementação do Sistema Nacional de Recursos Hídricos (SNRH). Por sua vez, o SNRH deve ser operacionalizado a partir de cinco instrumentos de gestão dos recursos hídricos: i) plano de recursos hídricos; ii) outorga pelo uso da água; iii) enquadramento dos corpos d'água em classes de uso; iv) sistema de informaçóes em recursos hídricos; e v) cobrança pelo uso da água.

Anteriormente à PNRH, o marco legal de recursos hídricos no Brasil era regulado pelo Código das Águas de 1934, que tratava de aspectos mais ligados a conflitos pontuais pelo uso da água (GARRIDO, 2000). Dentre as principais mudanças que ocorreram a partir da promulgação da PNRH, destaca-se: i) a água é um bem público, finito e dotado de valor econômico; ii) a preconização da participação social a partir do princípio da descentralização, com a instituição legal dos Comitês de Bacia Hidrográfica no âmbito dos Sistemas de Recursos Hídricos; e iii) a gestão das águas integrada com as políticas setoriais e compartilhada entre os entes federados, contemplando de forma indissociada as águas superficiais e subterrâneas.

O Sistema de Recursos Hídricos deve ser instituído em níveis Federal (SNRH) e Estadual (SERH). O mesmo compreende uma estrutura setorial com órgão gestor (instância administrativa e operacional), conselhos de recursos hídricos (instância política e deliberativa estadual) e comitês de bacia (instância política e deliberativa local), conforme a legislação federal e de cada estado. Destaca-se que os Comitês já estavam constituídos antes da promulgação da PNRH. Assim, o caráter descentralizador da PNRH, presente desde a sua concepçáo e elaboração, faz parte da essência da política.

A descentralização não foi prevista apenas no âmbito administrativo, mas, também, na ordem técnica, na medida em que as Políticas de Recursos Hídricos previram a criação das Agências de Bacia. Estes órgãos teriam a função de assessorar e subsidiar os Comitês e o órgão gestor Estadual na elaboração de estudos técnicos, econômicos e financeiros.

\section{Política de Proteção e Defesa Civil}

O processo de institucionalizaçáo da Defesa Civil no Brasil, de acordo com Almeida (2015), tem início na década de 40, com as primeiras açóes empreendidas pelo Estado em função da 2a Guerra Mundial. Apenas na década de 60 que se iniciam açóes mais estruturadas em funçáo das secas e cheias, sendo que em 1966 é fundada a primeira Defesa Civil no Brasil, no Estado da Guanabara. A partir da CF/88 o Estado, pela primeira vez, assume como prerrogativa da Uniấo: "planejar e promover a defesa permanente 
contra as calamidades públicas, em especial secas e inundaçóes, bem como legislar sobre a defesa civil”.

Em 16 de dezembro de 1988, nasceu o primeiro desenho sistêmico do que viria a ser o Sistema Nacional de Defesa Civil. Em virtude dos avanços significativos foi reorganizado em agosto de 1993 e atualizado pelo Decreto $n^{\circ} 5.376$, de 17 de fevereiro de 2005. Em 2010, com a Lei no 12.340 , deixou de ser regido por Decreto e passa a ter a força da Lei. (PNUD, 2012)

No ano de 2012, motivada, dentre outros aspectos, pelos desastres naturais extremos ocorridos em Santa Catarina no ano de 2008 e Rio de Janeiro em 2011 (ALMEIDA, 2015), a Lei 12.608/2012 instituiu a PNPDEC e o Sistema Nacional de Proteção e Defesa Civil (SNPDEC). Assim, o mesmo setor alterou o nome oficial de Defesa Civil para Proteção e Defesa Civil.

O SNPDEC se articula nos três níveis de governo, sendo composto por órgãos e entidades da administração pública federal, dos Estados, do Distrito Federal e dos Municípios, por entidades privadas e pela comunidade. Neste âmbito há uma distribuição de competências e a necessidade de articulação entre os entes federados, sendo o órgão central do Sistema a Secretaria Nacional de Defesa Civil (SEDEC) do Ministério da Integração Nacional.

De um modo geral, pode-se afirmar que a Lei $12.608 / 2012$, herdou uma diretriz de uma política de comando e controle. Esta afirmação corrobora com os principais desafios da área de gestão dos riscos de desastres no Brasil, elencados por PNUD (2012), quais sejam: a ausência significativa de cultura de prevenção de riscos no país; açóes e planos focados a emergências e respostas, aplicados de forma isolada e desconectada, tanto no nível estadual quanto municipal; e necessidade de ampliação do conhecimento sobre riscos e desastres, compartilhando base de dados confiáveis e continuamente alimentadas, com todos os segmentos envolvidos.

\section{Política de Saneamento}

A Lei 11.445/2007 dispóe sobre as diretrizes básicas do saneamento ambiental no Brasil, sobre a PFSB e o Sistema Nacional em Informaçóes em Saneamento (SNIS), coordenado pelo Ministério das Cidades. No ano de 2010 a referida Lei foi regulamentada pelo Decreto 7.217 (Brasil, 2010).
A evolução histórica da Política de Saneamento Básico no Brasil pode ser observada em Salles (2009), desde a criação do Plano Nacional de Saneamento PLANASA (1969), passando pela promulgação da $\mathrm{CF} / 1988$, por um período de amplos debates em torno de Projetos de Lei no sentido da desestatizaçáo e para implementar a Política Nacional de Saneamento Básico (PNSB) durante a década de 90 e início dos anos 2000, culminando na promulgaçáo da LDNSB no ano de 2007 pela Lei 11.445. Apesar de apresentar alguns avanços, notadamente em termos de estruturação normativa do setor, a LDNSB praticamente manteve o arranjo institucional e mecanismos de operação já existentes, onde as principais operadoras do saneamento no Brasil consistem nas Companhias Estaduais.

Rigorosamente falando, a LDNSB não pode ser considerada como uma Política Nacional para o setor de saneamento, tal como a PNRH e a PNPDEC. Diferente das demais, os serviços de saneamento não são de competência apenas da União. No art. XX da $\mathrm{CF} / 88$ observa-se que os serviços de interesse local são de competência municipal. Sendo que dentre os serviços de interesse local pode se incluir os serviços de saneamento (MEIRELLES, 2003; STF 2013c, 2013a, e 2013b). Portanto, a Lei no $11.445 / 2007$ prevê que cabe a quem detém a competência, disciplinar, efetivamente, $o$ assunto. As diretrizes federais não podem ser contrariadas pelos estados ou municípios, mas, também, elas não podem invadir a competência desses (ASSUMPÇÃO, 2017).

\section{INTERFACES ENTRE TRÊS POLÍTICAS}

A interface ou intersetorialidade entre as políticas públicas pode ser definida como o resultado da articulação entre instituições governamentais e entre essas e a sociedade civil (NASCIMENTO, 2010). O desenvolvimento destas interfaces no processo de gestão encontra tanto potencialidades como resistências, tais como: i) a articulação de saberes técnicos e o compartilhamento de agendas coletivas e objetivos comuns; ii) o potencial aumento da eficiência na organização logística das ações e na organização de políticas centradas em determinados territórios; iii) surgimento de novos problemas e desafios relacionados à superação da fragmentação e à articulação das políticas públicas, isto por conta da própria cultura, dificuldades político- 
-partidárias e outras questôes que vão incidir sobre a execução das políticas, como por exemplo mecanismos lobistas; e iv) o fato de que a intersetorialidade náo pode ser considerada antagônica ou substitutiva da setorialidade, mas complementar (SPOSATI, 2006; NASCIMENTO, 2010).

A Gestão dos Riscos de Desastres (GRD) possui característica intersetorial, uma vez que em seu contexto emergem aspectos relacionados tanto ao ambiente natural como à ocupação humana. Em um ambiente multissetorial de gestão, as interaçóes entre os agentes de vários níveis, conforme Saravanan (2008), ocorrem em contexto específico e são influenciadas por processos históricos, pelo contexto social e por fatores ecológicos.

No ano de 2003, a Secretaria Interinstitucional da Estratégia Internacional para a Redução de Riscos da Organização das Naçóes Unidas (EIRD/ONU), conjuntamente com o Programa das Naçôes Unidas para o Desenvolvimento (PNUD) elaborou um Marco de Ação para Orientar e Monitorar a Redução de Riscos de Desastres (EIRD/ONU, 2004). A metodologia de EIRD/ONU (2004) foi desenvolvida a partir da observação da experiência de diferentes países e a EIRD apresenta uma avaliação contínua a partir de informes anuais. O referido Marco de Ação fornece bases para o desenvolvimento de políticas nacionais e internacionais através da determinação de uma base mínima de informação sobre os riscos e vulnerabilidades.

O Marco de Ação foi estruturado com 5 áreas temáticas (Tabela 1). Salienta-se que o Marco apresenta, dentre seus objetivos, harmonizar e sistematizar os diversos elementos e resultados obtidos no âmbito da gestão geral de riscos de desastres. $\mathrm{O}$ presente artigo, portanto, utilizou as áreas temáticas do Marco para orientar a análise das interfaces.

Na seção a seguir, é explicitado como a metodologia da EIRD/ONU (2004) foi utilizada para a aplicação, reprodução e entendimento das análises desse trabalho.

Aspectos metodológicos da aplicação do Marco de Ação da EIRD/ONU junto ao presente trabalho

As características e critérios de referência orientadores para a sistematização dos elementos de cada política nas áreas temáticas do Marco encontram-se elencados em EIRD/ONU (2004).

A partir desta sistematização, a análise foi orientada para: o reconhecimento de informaçóes e dados com possibilidade de integração setorial; a captação e difusão de tendências em matéria de práticas de redução de
Tabela 1- Áreas temáticas do Marco de Ação para orientar e monitorar a redução de riscos de desastres (EIRD/ONU, 2004)

\begin{tabular}{|c|c|}
\hline Áreas Temáticas & Descrição \\
\hline $\begin{array}{c}1 \text { - Compromisso } \\
\text { político e } \\
\text { desenvolvimento } \\
\text { institucional } \\
\text { (governabilidade). }\end{array}$ & $\begin{array}{c}\text { Definida em termos de } \\
\text { compromisso político e } \\
\text { institucional fortes. Espera-se } \\
\text { que uma boa governabilidade } \\
\text { eleve a redução do risco de } \\
\text { desastres como prioridade } \\
\text { política e destine recursos } \\
\text { para tal. }\end{array}$ \\
\hline $\begin{array}{l}2 \text { - Identificação } \\
\text { e avaliação de } \\
\text { riscos. }\end{array}$ & $\begin{array}{l}\text { É uma área relativamente } \\
\text { bem definida que conta com } \\
\text { um conhecimento básico } \\
\text { sobre os métodos para } \\
\text { determinar o impacto dos } \\
\text { desastres e avaliar os riscos. } \\
\text { A avaliação sistemática dos } \\
\text { impactos e dos riscos é } \\
\text { fundamental para orientar as } \\
\text { ações. }\end{array}$ \\
\hline $\begin{array}{l}3 \text { - Gestão do } \\
\text { conhecimento }\end{array}$ & $\begin{array}{l}\text { A gestão e comunicação da } \\
\text { informação, a educação, a } \\
\text { capacitação, a consciência } \\
\text { política e a pesquisa são parte } \\
\text { do aperfeiçoamento e da } \\
\text { gestão do conhecimento sobre } \\
\text { os riscos e sua redução. }\end{array}$ \\
\hline $\begin{array}{c}4 \text { - Aplicação e } \\
\text { instrumentos na } \\
\text { gestão de riscos. }\end{array}$ & $\begin{array}{l}\text { Os instrumentos da gestão } \\
\text { de riscos são implementados } \\
\text { especialmente com o } \\
\text { reconhecimento da gestão } \\
\text { ambiental, redução da } \\
\text { pobreza e ferramentas de } \\
\text { gestão financeira. }\end{array}$ \\
\hline $\begin{array}{l}5 \text { - Planos de } \\
\text { contingência } \\
\text { e gestão de } \\
\text { emergências }\end{array}$ & $\begin{array}{l}\text { Espera-se que um sistema } \\
\text { bem preparado possua um } \\
\text { efetivo sistema de alerta, } \\
\text { planos de preparação local } \\
\text { e nacional e sistemas de } \\
\text { comunicação e coordenação } \\
\text { simulados regularmente. }\end{array}$ \\
\hline
\end{tabular}


Tabela 2 - Interfaces entre a PNRH, PNPDEC e a LDNSB na Área Temática 1: Compromisso político e desenvolvimento institucional (governabilidade)

\begin{tabular}{|c|c|c|c|}
\hline Componentes & PNRH & PNPDEC & LDNSB \\
\hline $\begin{array}{c}\text { Política e } \\
\text { planejamento }\end{array}$ & $\begin{array}{l}\text { Prevenção e a defesa } \\
\text { contra eventos } \\
\text { hidrológicos críticos. } \\
\text { Integração dos } \\
\text { processos de } \\
\text { planejamento setoriais. } \\
\text { Gestão } \\
\text { descentralizada, } \\
\text { participativa e } \\
\text { compartilhada. } \\
\text { Planos de Bacia, } \\
\text { Estadual e Federal. }\end{array}$ & $\begin{array}{c}\text { Reduzir os riscos de } \\
\text { desastres. } \\
\text { Integração com políticas } \\
\text { setoriais correlatas. } \\
\text { Gestão compartilhada, } \\
\text { participação social, e } \\
\text { descentralização. } \\
\text { Planos em escala } \\
\text { Nacional e Estadual e } \\
\text { Municipal. }\end{array}$ & $\begin{array}{c}\text { Universaliza-ção dos } \\
\text { serviços. } \\
\text { Integração e articulação } \\
\text { institucional. } \\
\text { Gestão compartilhada, } \\
\text { participativa e } \\
\text { descentralizada. } \\
\text { Planos Nacional, Regionais/ } \\
\text { Estaduais e Municipais. }\end{array}$ \\
\hline $\begin{array}{l}\text { Marco jurídico e } \\
\text { regulatório }\end{array}$ & $\begin{array}{c}\text { CF, art. 21, inc. XIX. Lei } \\
9.433 / 1997 \text { e Lei } \\
9.984 / 2000\end{array}$ & $\begin{array}{c}\text { CF, art. 21, inc. XVIII. } \\
12.608 / 2012\end{array}$ & $\begin{array}{l}\text { CF, art. 21, inc. XX e art. 23, } \\
\text { inc IX. Lei } 11.445 / 2007 .\end{array}$ \\
\hline Recursos & $\begin{array}{c}\text { Recursos não- } \\
\text { onerosos (LOA/OGU, } \\
\text { e orçamento dos } \\
\text { estados). } \\
\text { Cobrança pelo uso da } \\
\text { água. } \\
\text { Recursos da } \\
\text { compensação } \\
\text { financeira do setor } \\
\text { energético. } \\
\text { Empréstimos } \\
\text { internacionais. }\end{array}$ & $\begin{array}{l}\text { Recursos não-onerosos } \\
\text { (LOA/OGU, estados e } \\
\text { municípios). } \\
\text { FUNCAP. } \\
\text { Transferência de } \\
\text { recursos da União ao } \\
\text { Município para terrenos } \\
\text { para habitação. } \\
\text { Empréstimos } \\
\text { internacionais. }\end{array}$ & $\begin{array}{l}\text { Recursos não-onerosos } \\
\text { (LOA/OGU, estados e } \\
\text { municípios). } \\
\text { Recursos onerosos dos } \\
\text { fundos financiadores. } \\
\text { Emprést. Internacionais. } \\
\text { Recursos próprios dos } \\
\text { prestadores (superávits } \\
\text { arrecadação). }\end{array}$ \\
\hline $\begin{array}{c}\text { Estruturas } \\
\text { institucionais }\end{array}$ & $\begin{array}{c}\text { SRH/MMA (formulador } \\
\text { de Políticas). } \\
\text { ANA e órgãos gestores } \\
\text { estaduais (implementa } \\
\text { política). } \\
\text { CNRH; CERHs; } \\
\text { Comitês de Bacia } \\
\text { (CBHs) (órgãos } \\
\text { consultivos e } \\
\text { deliberativos). }\end{array}$ & $\begin{array}{c}\text { SEDEC/MI (formula e } \\
\text { implementa Políticas). } \\
\text { Órgão gestores } \\
\text { Estaduais e Municipais } \\
\text { (formula e implementa } \\
\text { política). } \\
\text { CONPEDEC (órgão } \\
\text { consultivo). } \\
\text { Órgãos setoriais do } \\
\text { poder público e org. } \\
\text { sociais. }\end{array}$ & $\begin{array}{l}\text { SNSA/MIC (formula e } \\
\text { acompanha Políticas). } \\
\text { ConCidades, Conselhos } \\
\text { Estadual, Municipal } \\
\text { (consultivo). } \\
\text { Titulares (implementa, } \\
\text { acompanha, fiscaliza); } \\
\text { Prestadores (implementa } \\
\text { política). } \\
\text { Entidades Reguladoras } \\
\text { (fiscaliza). }\end{array}$ \\
\hline
\end{tabular}

Obs.: LOA: Lei OrçamentáriaAnual; OGU: Orçamento Geral da União; SRH: Secretaria de Recursos Hídricos; MMA: Ministério de Meio Ambiente; ANA: Agência Nacional de Águas; CNRH e CERH: Conselhos Nacional e Estadual de Recursos Hídricos; SEDEC: Secretaria Nacional de Proteção e Defesa Civil; MI: Ministério da Integração Nacional; CONPEDEC: Conselho Nacional de Proteção e Defesa Civil; SNSA: Secretaria Nacional de Saneamento Ambiental; MIC: Ministério das Cidades; ConCidades: Conselho das Cidades. 
desastres; identificação de vazios e limitaçóes existentes para o processo de tomada de decisão.

Além disso, entende-se que o Marco desenvolvido por EIRD/ONU (2004) fornece bases metodológicas para uma análise que tem o potencial de: i) proporcionar diretrizes para ação política, assim como para a ação prática; ii) refletir a natureza multidimensional, interdisciplinar e de multiameaças da redução de desastres; iii) apoiar na determinação dos papéis e responsabilidades que as instituiçóes e a sociedade devem assumir em circunstâncias específicas; iv) auxiliar as instituiçóes e a sociedade na identificação de quais áreas devem se desenvolver capacidades; v) proporcionar as bases para o estabelecimento de metas e objetivos, adaptados aos diversos contextos.

\section{Área temática 1 - Compromisso político e desenvolvimento institucional}

Sob o enfoque desta área temática, a Tabela 2 resume as interfaces entre as três Políticas. Foram destacados os elementos identificados em cada política com maior potencial de interface, considerando os componentes de análise da Área Temática 1.

Os fundamentos, diretrizes e objetivos constituem-se como elementos-chave que orientam as Políticas Públicas. Em um exame das interfaces entre os fundamentos, diretrizes e objetivos dos marcos legais das três Políticas em análise (PNRH, PNPDEC e LDNSB), verifica-se que os seguintes aspectos comuns apresentam potencialidades no âmbito do fortalecimento da governabilidade por meio de sinergias, contribuindo para implementação de estratégias de redução de riscos de desastres (Figura 1).

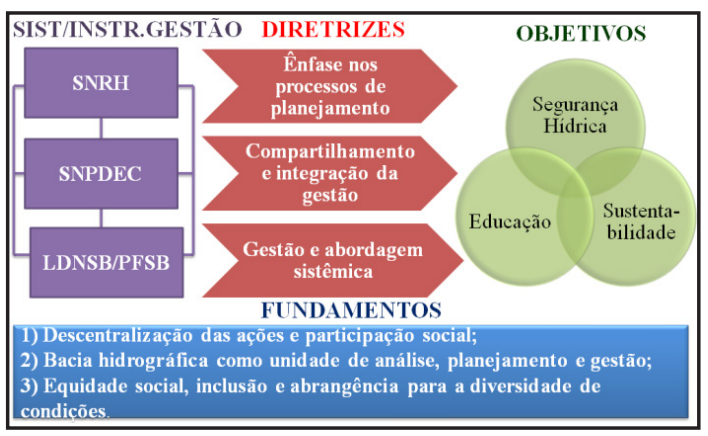

Figura 1- Interfaces entre a PNRH, PNPDEC e LDNSB com base nos seus respectivos Fundamentos, Diretrizes e Objetivos.
Forgiarini et al. (2007) entenderam que os Comitês de Bacia Hidrográfica, ao serem fortalecidos, dariam forma a uma identidade de bacia e se constituiriam como um fórum de encaminhamento dos pleitos setoriais para o desenvolvimento regional integrado. Neste âmbito, os fundamentos e diretrizes das políticas em análise demonstram convergência, no sentido da gestão integrada, participação social, segurança hídrica, dentre outros aspectos.

Em nível de planejamento, a PNRH possui instrumentos como os Planos de Recursos Hídricos ((Federal - SRH/MMA (2006) - já elaborado, Estaduais e em nível de Bacia)). Os Planos de Recursos Hídricos em geral, têm considerado em seus Programas, açóes para redução de riscos de desastres, no que diz respeito a zoneamento de áreas de inundação e implementação de sistemas de alerta, por exemplo, Plano de Bacia do Rio dos Sinos/RS (DRH/SEMA, 2014) e Plano da Bacia do Rio Paranapanema (ANA/2016).

A PNPDEC possui instrumentos como os Planos de Proteção e Defesa Civil em escala nacional e estadual, bem como Planos de Contingência e Plano de Implantação de Obras e Serviços para a redução de riscos de desastres em escala Municipal, além de exigências específicas para os Planos Diretores de Desenvolvimento Urbano de municípios cadastrados em área de risco.

Em termos de planejamento da Política de Saneamento, destaca-se existência do Plano Nacional (SNSA, 2014), Planos Regionais e Municipais. Ainda, neste âmbito, ressalta-se que a LDNSB exige que os Planos de Saneamento considerem o Plano de Recursos Hídricos quando da sua elaboração e/ ou atualização.

A União possui competência de instituir o SNRH e planejar e promover a defesa permanente contra as calamidades públicas, especialmente as secas e as inundaçôes. Deste modo, através das PNRH e PNPDEC, à União conseguiu estabelecer as competências das instituiçóes componentes do Sistema. Tal contexto não ocorre para a área de saneamento básico. Neste âmbito, compete a Uniāo instituir diretrizes para o desenvolvimento urbano, inclusive saneamento básico. Também compete à União legislar de modo concorrente com os Estados e Municípios sobre promover melhorias nas condições de saneamento básico.

Aos Municípios compete legislar, organizar e prestar serviços públicos de interesse local. O sanea- 
mento básico é considerado como de interesse local pelo jurista Meirelles (2003), bem como em decisôes proferidas pelo Superior Tribunal Federal, por exemplo, STF (2013a, 2013b).

Por sua vez, os Estados podem instituir regióes metropolitanas, aglomeraçóes urbanas e microrregiôes, para integrar a organização, o planejamento e a execução de funçóes públicas de interesse comum (Art. 25, $\$ 3$ da CF/88). Açóes dos Estados para assumir a titularidade de serviços de saneamento básico em regióes metropolitanas foram objetos de Ação Direta de Inconstitucionalidade (ADI), tais como as ADIs 1842 do Rio de Janeiro e 2077 (STF, 2013b) da Bahia (STF, 2013c). O resultado final do julgamento da ADI 1842 do Rio de Janeiro pelo STF se deu no sentido de que a gestáo, as questóes de titularidade e as açôes na área de saneamento básico devem ser compartilhadas entre Estados e Municípios no caso das regióes metropolitanas. As regras para a cooperação devem ser definidas pelos envolvidos em cada caso. A ADI da Bahia ainda está aguardando julgamento final.

No âmbito da organização municipal, destaca-se que a Lei $n^{\circ} 11.107 / 2005$ (BRASIL, 2005) (Lei de Consórcios Públicos) fornece regras gerais para a criação e operacionalização da gestão consorciada para implementação de Políticas Públicas. No âmbito da Política de Saneamento Básico existem diversos consórcios públicos municipais criados (SNSA, 2014).

Quanto aos recursos financeiros, têm-se como fontes comuns para as três Políticas os recursos não-onerosos da União e eventuais empréstimos internacionais.

Em especial a Política de Recursos Hídricos conta com recursos oriundos de royalties do setor de energia hidrelétrica e do instrumento econômico da cobrança pelo uso da água. Em geral os Sistemas Estaduais de Recursos Hídricos contam com um Fundo de Recursos Hídricos para gerenciar os recursos.

No caso da PNPDEC há o Fundo Especial para Calamidades Públicas (FUNCAP), criado em 1969 e regulamentado pelo Decreto no 1.080/1994 (BRASIL, 1994), o qual tem por finalidade financiar as ações de socorro, de assistência à população e de reabilitação de áreas atingidas. As açôes de prevenção, mitigação e preparação não são atendidas por este fundo, sendo, portanto, dependentes de recursos da União, Estados e Municípios. As regras para transferências dos recursos encontram-se na Lei $\mathrm{n}^{\circ} 12.340 / 2010$ (BRASIL, 2010).

Em particular, o setor de Saneamento é alvo de recursos mobilizados pelo setor público por meio dos fundos de poupança compulsória, por exemplo, o Fundo de Garantia do Tempo de Serviço (FGTS) e o Fundo de Amparo ao Trabalhador (FAT), denominados recursos onerosos (SNSA, 2014). Os fundos públicos de poupança compulsória têm sido utilizados, em vários países, para auxiliar o esforço de financiamento de diversas atividades de fomento, sobretudo em apoio àqueles setores cujo investimento é de alto risco, longo prazo de maturação ou, ainda, cujo retorno social é elevado relativamente ao retorno privado (IPEA, 1997). Outra particularidade do setor de saneamento é possibilidade de realização de investimento a partir de superávit.

Em termos de Sistema de Gestão e as respectivas instituições envolvidas na implementação das Políticas, a Figura 2 apresenta a sistematização das interfaces, tendo como base as competências definidas nas Leis 9.433/1997 (PNRH), 12.608/2012 (PNPDC), $11.445 / 2007$ (LDNSB) e Decreto 7.217/2010 o qual regulamenta a LDNSB. A faixa amarela nessa tabela apresenta a forte interface.

Os Conselhos geralmente são responsáveis pelo estabelecimento de diretrizes, podendo ter caráter consultivo e deliberativo, como o CNRH e o ConCidades, ou apenas consultivo como o CONPDEC. Ao contrário do nível nacional onde as três Políticas possuem Conselhos, apenas a Política de Recursos Hídricos possui Conselhos especificamente setoriais definidos por lei nos Estados (CERHs) e em bacias (CBHs). Tal situação confere à PNRH um diferenciado nível de descentralização em termos de participação social.

Quanto ao órgão responsável por implementar as políticas em nível nacional, a SEDEC e a ANA estão em um nível hierárquico similar no organograma da Política no que diz respeito a sua implementação. Já a SNSA, apesar de possuir o mesmo nível hierárquico da SEDEC e ANA, no que diz respeito ao planejamento, acompanhamento e gestão da implementação de diretrizes nacionais, não possui a competência para executar a Política, que fica a cargo dos Titulares/ Prestadores de Serviços. 


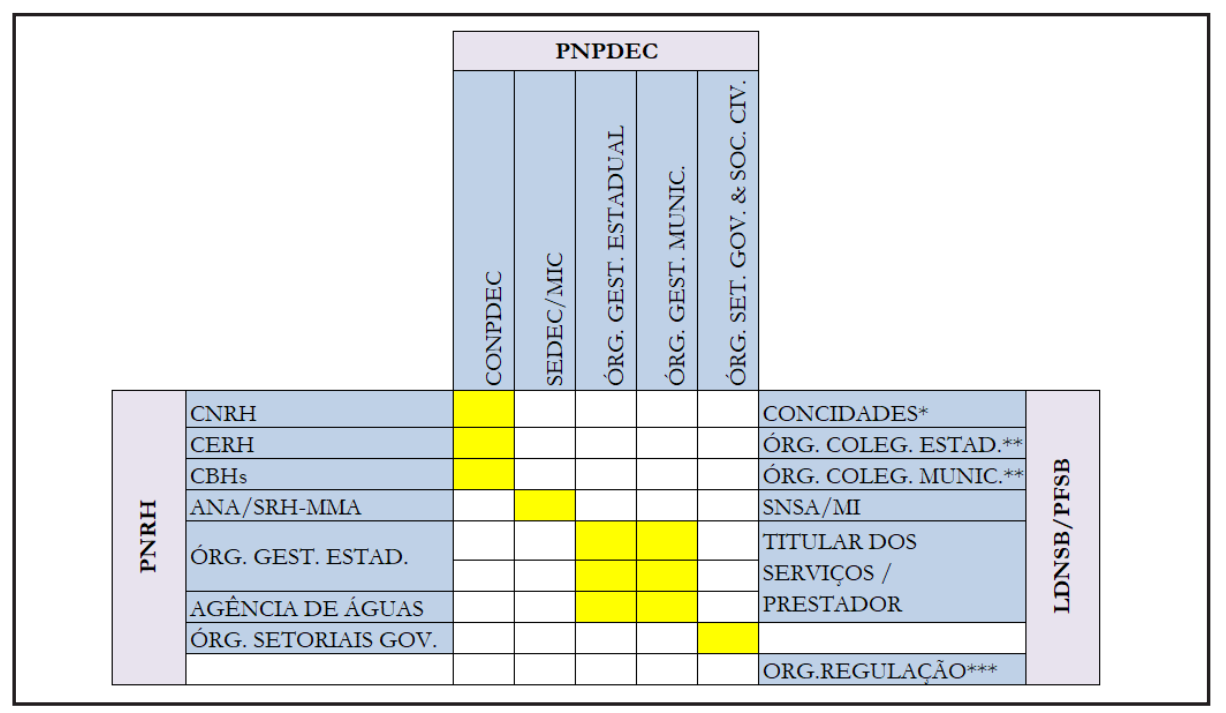

Figura 2 -Interfaces entre os órgãos e entidades componentes dos Sistemas de Recursos Hídricos, Proteção e Defesa Civil, e determinadas junto a LDNSB.

*O Conselho das Cidades (CONCIDADES) possui Comitê Técnico de Saneamento Ambiental coordenado pela SNSA, portanto foi considerado na instância nacional para a Política de Saneamento Básico, ainda que os Conselhos Nacionais de Saúde, Recursos Hídricos e Meio Ambiente também necessitem ser acionados para as tomadas de decisão, em especial do PLANSAB, conforme o Decreto 7217/2010 (Brasil, 2010). **A participação de entidades do setor de Saneamento em órgãos colegiados de outra Política (ex: CBHs) também é considerada pela LDNSB. Ou seja, a LDNSB não prevê, ainda que não exclua esta possibilidade, a existência de conselho federal, estadual ou municipal de saneamento básico. *** A regulação dos serviços de saneamento poderá ser delegada pelos titulares dos serviços.

\section{Área Temática 2 - Identificação e avaliação de riscos}

A Área Temática 2 é uma área relativamente bem definida que conta com um conhecimento básico sobre os métodos para determinar o impacto dos desastres e avaliar os riscos. Assim sendo, a avaliação sistemática dos impactos e dos riscos é fundamental para orientar as ações (EIRD/ONU, 2004).

Analisa-se esta Área Temática sob o enfoque de dois componentes: a) avaliação de riscos e qualidade dos dados; e b) a implementação de Sistemas de Alerta. O primeiro componente é caracterizado por incluir as estratégias, planos, programas e açóes relativos ao conhecimento do problema, diagnóstico e mapeamento do perigo, vulnerabilidade e riscos. $\mathrm{O}$ segundo inclui aspectos relacionados às atividades de monitoramento e predição de desastres, elaboração de cenários de riscos, emissão e difusão do alerta e a resposta ao alerta. Aqui, salienta-se que o conceito de risco varia entre as ciências, os setores, os pesquisadores, etc. Não há consenso do assunto ainda hoje (GOERL et al., 2012), o que pode representar um obstáculo no desenvolvimento da inter-setorialidade entre as políticas.

A Tabela 3 apresenta as interfaces entre as três Políticas no que diz respeito a esta Área Temática.

Os sistemas de informação e os diagnósticos e prognósticos elaborados no âmbito dos processos de planejamento das três Políticas, constituem-se em pontos em comum no que diz respeito ao Componente "Avaliação de riscos e qualidade dos dados". Os sistemas, estudos e os planos são desenvolvidos em escalas federal, estadual e municipal e por unidade de gestão de recursos hídricos, o que possibilita o desenvolvimento de estudos nas diversas escalas, conforme a necessidade (Tabela 3).

Em nível nacional, existem diferenças entre os sistemas relacionadas à operacionalidade. O SNIRH e o S2iD são acoplados a uma base de Sistema de Informaçóes Geográficas (SIG) on-line. O SNIS, apesar de não possuir uma ferramenta SIG, possibilita a organizaçáo dos dados de modo dinâmico e exportação dos dados para arquivos editáveis. As informaçóes no SNIRH são espacializadas por unidade de gestáo 
Tabela 3 - Interfaces entre a PNRH, PNPDEC e a LDNSB na Área Temática 2: Identificação e avaliação de riscos

\begin{tabular}{|c|c|c|c|}
\hline Componentes & PNRH & PNPDEC & LDNSB \\
\hline $\begin{array}{c}\text { Avaliação } \\
\text { de riscos e } \\
\text { qualidade dos } \\
\text { dados }\end{array}$ & $\begin{array}{l}\text { SNIRH e } \\
\text { SERHs. } \\
\text { Sala de } \\
\text { Situação (ANA } \\
\text { e Estados). } \\
\text { Planos } \\
\text { Nacional, } \\
\text { Estadual e de } \\
\text { Bacia. }\end{array}$ & $\begin{array}{c}\text { S2iD; } \\
\text { Planos Nacional, Estadual e } \\
\text { Municipal. } \\
\text { Cadastro nacional de municípios } \\
\text { com áreas suscetíveis. } \\
\text { Mapeamento das áreas de risco } \\
\text { (estados e municípios) } \\
\text { Carta geotécnica de aptidão à } \\
\text { urbanização (municípios). }\end{array}$ & $\begin{array}{l}\text { SNIS/SNSA e Sistemas } \\
\text { implement. pelos titulares. } \\
\text { Planos Nacional, Estadual, } \\
\text { Regional, Municipal. } \\
\text { Controle e vigilância da } \\
\text { qualidade da água, Plano de } \\
\text { Segurança da Água (PSA) } \\
\text { (implementa Titular/Prest.) }\end{array}$ \\
\hline $\begin{array}{l}\text { Sistema de } \\
\quad \text { alerta }\end{array}$ & $\begin{array}{c}\text { Sala de } \\
\text { Situação (ANA } \\
\text { e Estados); }\end{array}$ & $\begin{array}{l}\text { S2iD/SEDEC. (Monitoramento } \\
\text { efetuado pelo CEMADEN e } \\
\text { gerenciado pelo CENAD). } \\
\text { Planos de Contingência de Proteção } \\
\text { e Defesa Civil (municípios). }\end{array}$ & $\begin{array}{l}\text { Controle e vigilância da } \\
\text { qualidade da água, PSA } \\
\text { (implementa Titular/Prest.) } \\
\text { Monitoram. divulgado para } \\
\text { sociedade (ex: CESAN) }{ }^{\star *} \text {. }\end{array}$ \\
\hline
\end{tabular}

Obs.: SNIRHIANA: Sistema Nacional de Informações sobre Recursos Hídricos; SEIRHs: Sistemas Estaduais de Informações sobre Recursos Hídricos; S2iDISEDEC: Sistema Integrado de Informações sobre Desastres; SINSISNSA: Sistema Nacional de Informações sobre Saneamento; CENADEN: Centro Nacional de Monitoramento e Alerta de Desastres Naturais; CENAD: Centro Nacional de Gerenciamento de Riscos e Desastres; CESAN: Companhia Espírito Santense de Saneamento; PSA: Plano de Segurança de Água.

*Os serviços de monitoramento e previsão efetuados pelo CEMADEN por meio de sua Sala de Situação (http:IIwww. cemaden.gov.brlsala-de-operacaol) subsidiam o CENAD, que gerencia a emissão e difusão do alerta e é ligado ao MI. Contudo, o CEMADEN não está inserido no âmbito da estrutura institucional da PNPDEC, sendo ligado ao Ministério da Ciência, Tecnologia, Inovações e Comunicações (http://www.cemaden.gov.brl).

**. A CESAN apresenta diariamente os níveis d'água dos principais mananciais de abastecimento da Região Metropolitana de Vitória: http://www.cesan.com.br/vazao-media-diaria-captadal.

e trecho de rio, sendo possível exportar arquivos em formato manipulável por meio de geoprocessamento (ex: shapefile). Porém, tanto no S2iD como no SNIS as informaçốes estão espacializadas por município e o arquivo shapefile deve ser criado pelo próprio usuário. Isto dificulta uma análise rápida integrada da situação dos riscos por bacia hidrográfica - sendo que a bacia é reconhecida como unidade de gestão pelas três Políticas Nacionais.

No contexto da integração dos dados espaciais produzidos no âmbito de cada política setorial, foi instituída pelo Decreto Federal 6.666/2008 (BRASIL, 2008) a Infraestrutura Nacional de Dados Espaciais (INDE). A gestão e coordenação da INDE são realizadas pelo Ministério do Planejamento, Orçamento e Gestão por intermédio da Comissão Nacional de Cartografia (CONCAR), do Instituto Brasileiro de Geografia e Estatística (IBGE) e a Secretaria de Planejamento e Investimentos Estratégicos (SPI).
Em consulta realizada junto à base de dados do INDE em setembro de 2017, foi verificada uma situaçáo de desuniformidade da qualidade da informação no que diz respeito aos dados de base das três Políticas em análise.

O setor de Recursos Hídricos encontra-se mais avançado em termos de disponibilização de quantidade e qualidade da informaçáo, uma vez que significativa parcela das informaçóes do SNIRH/ANA encontram-se integradas ao INDE.

Tal situação não é observada no que diz respeito ao SNIS e ao S2iD. O SNIS apresenta uma série histórica de dados de saneamento de 1995 até 2015, porém as informaçóes de saneamento disponibilizadas no INDE são de 2008, sendo oriundas do IBGE e espacializadas por município. Já quanto ao $\mathrm{S} 2 \mathrm{iD}$ são espacializadas por município as açôes do Plano Nacional de Gestão de Riscos e Respostas a Desastres Naturais, porém não há descrição a respeito da ação, a qual deve ser obtida junto ao próprio documento do Plano, indisponível na web. 
Cabe ressaltar que tanto a PNPDEC quanto a LDNSB reconhecem a importância da bacia hidrográfica como unidade de planejamento e gestão, porém, não consideram esse nível na espacialização nos respectivos Sistemas de Informação.

Os estudos, planos, mapeamentos e sistemas de informação desenvolvidos no âmbito das três Políticas encontram-se sintetizados na Figura 3.

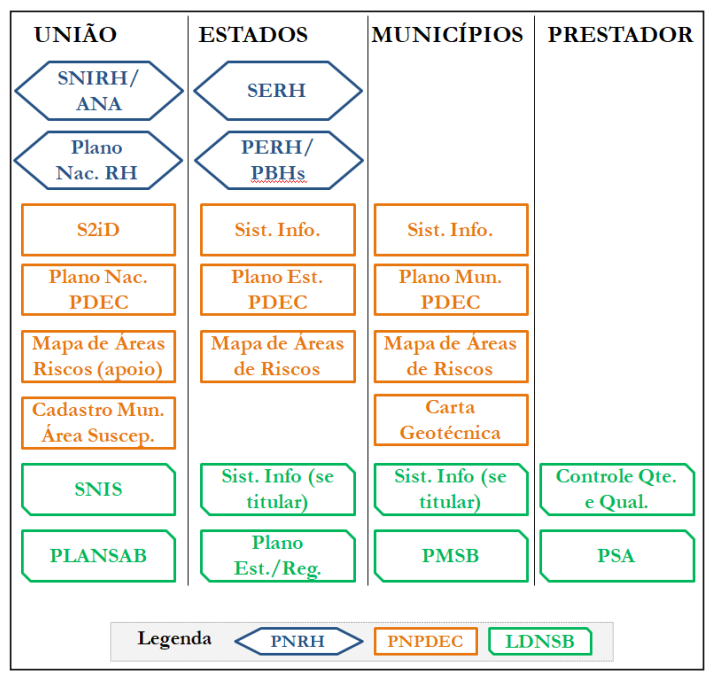

Figura 3 - Síntese das Interfaces para o componente Avaliação de Riscos e Qualidade dos Dados.

Obs: PERH: Plano Estadual de Recursos Hídricos; PBH: Plano de Bacia Hidrográfica. PMSB: Plano Municipal de Saneamento Básico.

Em relação ao segundo componente - Sistema de Alerta, as atividades de monitoramento no âmbito da PNRH são realizadas pela ANA por meio da implementação da rede hidrológica nacional, sendo a predição e cenários elaborados por meio das Salas de Situação - implantadas em parceria com os Estados. A própria Sala de Situação prevê integração com o CEMADEN, CENAD e com as Proteçôes e Defesas Civis Estaduais e Municipais, para fins de análise dos cenários. A emissão e difusão do alerta devem ser operacionalizadas pelo CENAD (União) e Proteção e Defesas Civis Municipais, contando com apoio dos Estados.

No âmbito da Política de Saneamento, a previsão da realização de monitoramento ocorre apenas no âmbito da qualidade da água para consumo humano, porém devido à indissociabilidade da qualidade com a quantidade da água, bem como para garantia do atendimento à demanda, os aspectos quantitativos também são monitorados.
Não há obrigatoriedade de comunicação contínua (ex: diária) à sociedade dos níveis d'água monitorados, contudo encontram-se iniciativas em nível estadual e regional desta prática, por exemplo, CESAN/ES (2017) e COMITESINOS (2017), este último inserido na PNRH.

Observa-se uma tendência internacional quanto à elaboração de Planos de Segurança da Água (PSA), os quais consistem em uma abordagem ampla do sistema de abastecimento da água, incluindo a avaliação dos riscos e seu respectivo gerenciamento a fim de proteger a saúde pública (OMS, 2017). Ainda, conforme OMS (2017), o PSA foi objeto de açóes para sua implementaçáo em cerca de 118 países.

A LDNSB delegou ao Ministério da Saúde a determinaçáo dos procedimentos de controle de qualidade da água. No âmbito destes procedimentos, a Portaria MS 2914/2011 (MS, 2011) explicita a necessidade de o responsável pelo sistema ou pela solução alternativa de abastecimento de água para consumo humano manter avaliação sistemática do sistema sob a perspectiva dos riscos à saúde, com base na qualidade da água distribuí$\mathrm{da}$, conforme os princípios dos PSA recomendados pela OMS ou definidos em diretrizes vigentes no País. O Brasil se tornou assim, o primeiro país do mundo a incorporar o tema PSA em legislação nacional (MS/SVS, 2011).

Uma interface bem definida com o componente "Sistemas de Alerta" é que, segundo a Portaria MS 2914/2011, o responsável pela operação do sistema deve monitorar, fornecer dados e comunicar aos órgãos ambientais, aos gestores de recursos hídricos e ao órgão de saúde pública dos Estados e dos Municípios qualquer alteração da qualidade da água no ponto de captação que comprometa a tratabilidade da água para consumo humano. Além disso, deve dispor de canal de comunicação com a população para recebimento de reclamaçốes e informaçôes sobre a qualidade das águas. A Figura 4 sintetiza as interfaces entre as três Políticas com relação ao componente Sistema de Alerta.

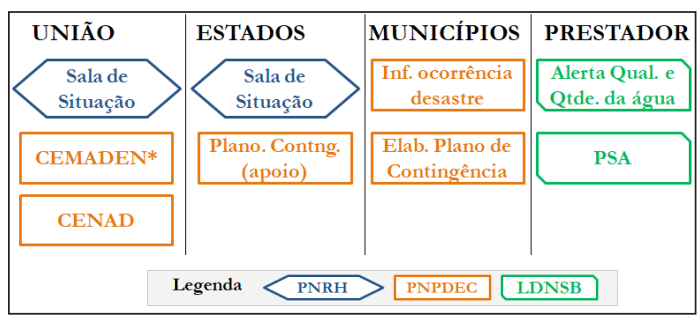

Figura 4 - Síntese das interfaces para o componente Sistema de Alerta 


\section{Área Temática 3 - Gestão do conhecimento}

A Área 3 aborda a gestão e comunicação da in- formação, a educação, a capacitação, a consciência política e a pesquisa no âmbito das Políticas. A Tabela 4 apresenta as interfaces identificadas para essa área.

Tabela 4 - Interfaces entre a PNRH, PNPDEC e a LDNSB na Área Temática 3: Gestão do conhecimento

\begin{tabular}{|c|c|c|c|}
\hline Componentes & PNRH & PNPDEC & LDNSB \\
\hline $\begin{array}{c}\text { Gestão e } \\
\text { comunicação } \\
\text { da informação }\end{array}$ & $\begin{array}{c}\text { Execução Programas } \\
\text { do Plano Nac. Rec. Hídr. } \\
\text { (SRH/ MMA 2009). } \\
\text { Programas de } \\
\text { Capacitação do SINGREH } \\
\text { (ex: Acervo Educacional } \\
\text { sobre Água - ConheceRH) } \\
\text { SNIRH/ANA e SEIRHs. } \\
\text { Apoio e Realização de } \\
\text { Eventos. }\end{array}$ & $\begin{array}{c}\text { Execução Programas do } \\
\text { PPA. 2016-2019 (Brasil, } \\
\text { 2016). } \\
\text { S2iD. } \\
\text { CENAD. } \\
\text { Atividades Comemorativas } \\
\text { (Ex: Semana Nacional de } \\
\text { Redução de Desastres - } \\
\text { Dec. 26/2005 (Brasil, 2005). } \\
\text { Publicações } \\
\text { disponibilizadas on-line pela } \\
\text { SEDEC. } \\
\text { Apoio e Realização de } \\
\text { Eventos. }\end{array}$ & $\begin{array}{c}\text { Execução Programas do } \\
\text { PLANSAB. } \\
\text { SNIS. } \\
\text { Trabalho Social nos } \\
\text { empreendimentos de } \\
\text { Saneamento, regulado } \\
\text { pela Portaria MCidades } \\
n^{\circ} \text { 21/2014 (MCIDADES, } \\
\text { 2014). } \\
\text { Apoio e Realização de } \\
\text { Eventos. }\end{array}$ \\
\hline $\begin{array}{l}\text { Educação e } \\
\text { capacitação }\end{array}$ & $\begin{array}{l}\text { Programas de } \\
\text { Capacitação do } \\
\text { SINGREH. }\end{array}$ & $\begin{array}{l}\text { Cursos de Capacitação p/ } \\
\text { comunidades e técnicos. } \\
\text { Inserção da proteção e } \\
\text { defesa civil nos currículos } \\
\text { escolares (Brasil, 2012). }\end{array}$ & $\begin{array}{c}\text { Programa Nacional de } \\
\text { Capacitação das Cidades } \\
\text { (CAPACIDADES). } \\
\text { Elaboração de Manuais } \\
\text { Técnicos (SNSA). }\end{array}$ \\
\hline $\begin{array}{l}\text { Consciência } \\
\text { política }\end{array}$ & - & - & - \\
\hline $\begin{array}{c}\text { Investigação/ } \\
\text { Pesquisa }\end{array}$ & $\begin{array}{c}\text { Cooperação Técnica } \\
\text { Internacional (ex: PNUD, } \\
\text { IHP). } \\
\text { Programas de } \\
\text { Capacitação do SINGREH, } \\
\text { em especial a Cooperação } \\
\text { Interinstitucional (Ex: } \\
\text { Estratégias de apoio a } \\
\text { pós-graduação) } \\
\text { CT-Hidro**. } \\
\text { Participação em e eventos. } \\
\text { Programa INTERÁGUAS. }\end{array}$ & $\begin{array}{c}\text { Cooperação Técnica } \\
\text { Internacional (ex: PNUD, } \\
\text { EIRD). } \\
\text { Participação em eventos. } \\
\text { Projetos de Cooperação } \\
\text { entre o poder público e } \\
\text { com Universidades (ex: } \\
\text { CEPED). } \\
\text { Redes de Cooperação } \\
\text { com Poder Público, } \\
\text { Universidade e Ministério } \\
\text { Público. } \\
\text { Programa INTERÁGUAS. }\end{array}$ & $\begin{array}{c}\text { Cooperação Técnica } \\
\text { Internacional (ex: PNUD). } \\
\text { Estudos e Pesquisas em } \\
\text { Saneamento (SNSA). } \\
\text { Parcerias e redes de } \\
\text { cooperação. } \\
\text { Programa INTER-ÁGUAS. }\end{array}$ \\
\hline
\end{tabular}

Obs: SINGREH: Sistema Nacional de Gerenciamento de Recursos Hídricos; PNUD: Programa das Nações Unidas para o Desenvolvimento; CT-Hidro: Fundo de Recursos Hídricos; Programa INTERÁGUAS: Programa de Desenvolvimento do Setor Água. CEPED: Centro de Estudos e Pesquisas sobre Desastres.

*A partir de 2014 a ANA iniciou estratégias de apoio à criação e fortalecimento de cursos de pós-graduação, em nível de especialização e mestrado profissional: i) Especialização em Elaboração e Gerenciamento de Projetos Municipais de Recursos Hídricos; ii) Mestrado Profissional em Gestão e Regulação de Recursos Hídricos - ProfÁgua; iii) Mestrado Profissional em Rede Nacional para o Ensino de Ciências Ambientais - ProfCiamb; e iv) Mestrado Profissional em Gestão de Riscos e Desastres Naturais.

** Embora o CT-Hidro não esteja institucionalmente no âmbito da PNRH, o mesmo foi destacado devido a sua relevância em termos de recursos para o setor de recursos hídricos. O CT-Hidro destina-se a financiar estudos e projetos na área de recursos hídricos. Sua fonte de financiamento é $4 \%$ da compensação financeira atualmente recolhida pelas empresas geradoras de energia elétrica. 
No âmbito dos Planos Nacionais desenvolvidos nas três Políticas, observam-se a existência de Programas relacionados à Gestáo do Conhecimento, bem como é prática comum o estabelecimento de acordos de cooperação com Universidades.

No que diz respeito à difusão da informação, tanto a PNRH como a LDNSB/PFSB, dispóem de Programas de Capacitação on-line, interativos e gratuitos.

Podem ser encontrados materiais para consulta junto aos sites dos órgãos gestores responsáveis em nível federal das três Políticas, o que facilita e amplia o acesso a informação. Em especial quanto à educação e capacitação, são realizadas açóes de capacitação com a população e profissionais de diversos níveis de escolaridade e nível de conhecimento técnico. No caso do SINGREH, por exemplo, são realizados desde jogos educativos até cursos de pós-graduação.

A tomada de consciência pública no âmbito das três Políticas em geral não tende a apresentar muitas variaçóes. De um modo geral, observa-se que a cobertura da própria mídia ocorre apenas durante ou após o evento de desastres.

Em termos de efetiva integração entre as três Políticas em análise, ressalta-se a implementação do Programa de Desenvolvimento do Setor Água - PROGRAMA INTERÁGUAS. Os órgãos executores desse Programa são o MMA/SRH/ANA, o MI/SEDEC/ SENIR e o MIC/SNSA, o que denota a efetiva ação inter-setorial em relação à água, tema comum que permeia as três políticas.

O programa, encontra-se em andamento e possui um prazo de 5 anos e orçamento de US\$ $143,11 \mathrm{mi}-$ lhôes bem distribuídos entre os seus 5 Componentes: 1) Gestão dos Recursos Hídricos; 2) Água, Irrigação e Defesa Civil; 3) Abastecimento de Água e Saneamento; 4) Açóes Intersetoriais e Planejamento Integrado e; 5) Gerenciamento, Monitoramento e Avaliação.

A Segurança Hídrica, sendo o tema principal da fase VIII do IHP da UNESCO, é um ponto de interface entre os objetivos das três Políticas, conforme verificado nos aspectos de governabilidade destacados na Área Temática 1. Deste modo, cabe ressaltar que dentre os produtos licitados pelo INTER-ÁGUAS, está em andamento o Plano Nacional de Segurança Hídrica, que objetiva inventariar a situação hídrica em termos de eventos hidrológicos extremos (inundaçôes e estiagens) e as medidas estruturais e não estruturais para garantia da segurança hídrica nos 26 estados brasileiros.

A educação apresenta um contexto transversal, conforme a própria Política Nacional de Educação (Lei 9.795/1999) (BRASIL, 1999). Neste contexto se inserem objetivos das legislaçóes nacionais das três políticas em análise, sendo observada uma preocupação em comum com a manutenção dos fundamentos e diretrizes das mesmas através de ações de gestão continuadas e vinculadas a açóes de educação.

A Figura 5 representa os aspectos com interface identificados para a Área Temática 3, ressaltando o programa INTERAGUAS como elemento integrador e que permeia diversos componentes dessa Área.

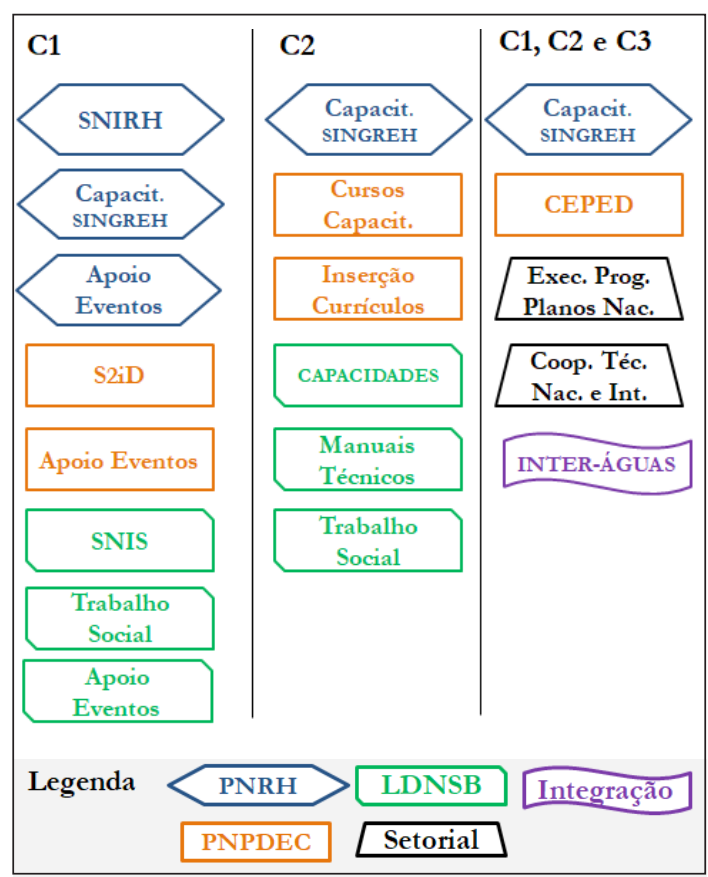

Figura 5 - Síntese das interfaces para a Área Temática 3 - Gestão do conhecimento.

Obs.: Componente C1: Gestão e Comunicação da informação; C2: Educação e capacitação; e C3: Investigação/Pesquisa.

\section{Área Temática 4 - Aplicação e instrumentos na gestão de riscos}

Os instrumentos da gestão de riscos são implementados especialmente com o reconhecimento da gestão ambiental, redução da pobreza e ferramentas de gestão financeira (EIRD/ONU, 
2004). Os instrumentos a serem aplicados para a gestão de riscos são abordados na Área 4 através de 3 componentes: 1) Gestão de recursos naturais e ambientais; 2) Práticas de desenvolvimento social e econômico; e 3) Medidas físicas e técnicas (Tabela 5).

O componente de gestão de recursos naturais e ambientais é bastante amplo. A gestão ambiental no Brasil é de responsabilidade do MMA. Os instrumentos de Zoneamento Ambiental e o Licenciamento Ambiental, da Lei 6.938/1981 - Política Nacional de Meio Ambiente (PNMA) (BRASIL, 1981), consideram aspectos das demais políticas relacionadas a características regionais da área objeto de zoneamento ou específicas de um dado empreendimento.
No que diz respeito às três Políticas em análise, a gestão dos recursos naturais e ambientais pode ser relacionada à aplicação dos próprios instrumentos de gestão das mesmas em conjunto com o pleno reconhecimento dos instrumentos da PNMA e da Lei 10.257/2001 - Política de Uso do Solo e Desenvolvimento Urbano (BRASIL, 2001).

Em relação às práticas de desenvolvimento social e econômico, ressalta-se o instrumento da cobrança pelo uso da água da PNRH. Este instrumento efetiva o princípio do poluidor pagador junto aos usuários da água e tem como premissa que os recursos arrecadados com a cobrança devem ser aplicados prioritariamente na bacia hidrográfica em que foram gerados. Deste modo, esta premissa tem o potencial de gerar o desenvolvimento social e econômico regional.

Tabela 5 - Interfaces entre a PNRH, PNPDEC e a LDNSB na Área Temática 4: Aplicação e instrumentos na gestão de riscos

\begin{tabular}{|c|c|c|c|}
\hline Componentes & PNRH & PNPDEC & LDNSB \\
\hline $\begin{array}{l}\text { Gestão de } \\
\text { recursos naturais e } \\
\text { ambientais }\end{array}$ & $\begin{array}{c}\text { Outorga. } \\
\text { Enquadr. } \\
\text { Implementação } \\
\text { instrumentos da Área } \\
\text { Temática } 2 .\end{array}$ & $\begin{array}{c}\text { Implementação } \\
\text { instrumentos da Área } \\
\text { Temática } 2 .\end{array}$ & $\begin{array}{l}\text { Implem. instrumentos } \\
\text { da Área Temática } 2 .\end{array}$ \\
\hline $\begin{array}{l}\text { Práticas de desenv. } \\
\text { social e econômico }\end{array}$ & $\begin{array}{l}\text { Cobrança pelo uso da água. } \\
\text { Implementação das práticas } \\
\text { da Área Temática } 3 . \\
\text { Apoio à implementação de } \\
\text { Comitês de Bacia. } \\
\text { Implementação de Fundos } \\
\text { de Recursos Hídricos } \\
\text { (Estados)*. }\end{array}$ & $\begin{array}{c}\text { Implementação das } \\
\text { práticas da Área Temática } \\
3 . \\
\text { Transferência de recursos } \\
\text { aos municípios para } \\
\text { aquisição de terrenos em } \\
\text { áreas de interesse social. } \\
\text { FUNCAP. } \\
\text { Fundos Estaduais* }\end{array}$ & $\begin{array}{c}\text { Implem. práticas Área } \\
\text { Temática } 3 . \\
\text { Implem. de Subsídios } \\
\text { Cruzados. }\end{array}$ \\
\hline $\begin{array}{c}\text { Medidas físicas e } \\
\text { técnicas }\end{array}$ & $\begin{array}{c}\text { Estudo, Planos e } \\
\text { Projetos relacionados a } \\
\text { Infraestrutura Hídrica (ex: } \\
\text { Atlas de Abastecimento } \\
\text { Urbano; Planos de } \\
\text { Recursos Hídricos). } \\
\text { Outorga e Fiscalização. } \\
\text { CERTOH. } \\
\text { Medidas físicas e técnicas } \\
\text { abordadas no Programa } \\
\text { Interáguas. }\end{array}$ & $\begin{array}{l}\text { Elaboração de Estudos } \\
\text { e Projetos e execução e } \\
\text { supervisão de obras. } \\
\text { Fiscalização de áreas de } \\
\text { risco e da ocupação. } \\
\text { Medidas físicas e técnicas } \\
\text { abordadas no Programa } \\
\text { Interáguas. }\end{array}$ & $\begin{array}{c}\text { Elaboração de Estudos } \\
\text { e Projetos e execução } \\
\text { e supervisão de obras. } \\
\text { Fiscalização dos } \\
\text { serviços. } \\
\text { Medidas físicas e } \\
\text { técnicas abordadas no } \\
\text { Programa Inter-águas. }\end{array}$ \\
\hline
\end{tabular}

Obs.: CERTOH: Certificado de Avaliação da Sustentabilidade da Obra Hídrica.

*Não está no âmbito da Política Nacional, sendo instrumento desenvolvido no âmbito da Política Estadual de alguns Estados. 
Por sua vez, a PNPDEC dispóe que é competência da União a transferência de recursos aos Municípios para aquisição de terrenos em áreas de interesse social. Tal prática pode contribuir para o desenvolvimento social e econômico, ao possibilitar a retirada de pessoas de áreas vulneráveis.

$\mathrm{Na}$ PFSB um modelo adotado desde o PLANASA são os subsídios cruzados, que possibilitam a utilizaçáo de superávits obtidos em áreas onde os serviços prestados apresentam maior escala e, consequentemente, maior resultado financeiro para o pagamento de déficits potenciais relacionados aos investimentos e a operaçáo em áreas com menor escala de prestação de serviços. Caso contrário não seria possível sob o ponto de vista financeiro-operacional, de acordo com o modelo atualmente adotado para o sistema de captação e distribuição de água, atender populações de municípios menores.

Quanto às medidas físicas e técnicas, apenas a PNRH não possui a execução de medidas estruturais diretas em seu escopo de atuação. Deste modo, os órgãos da PNRH, no que diz respeito a obras de infraestrutura, atuam no sentido do pla-

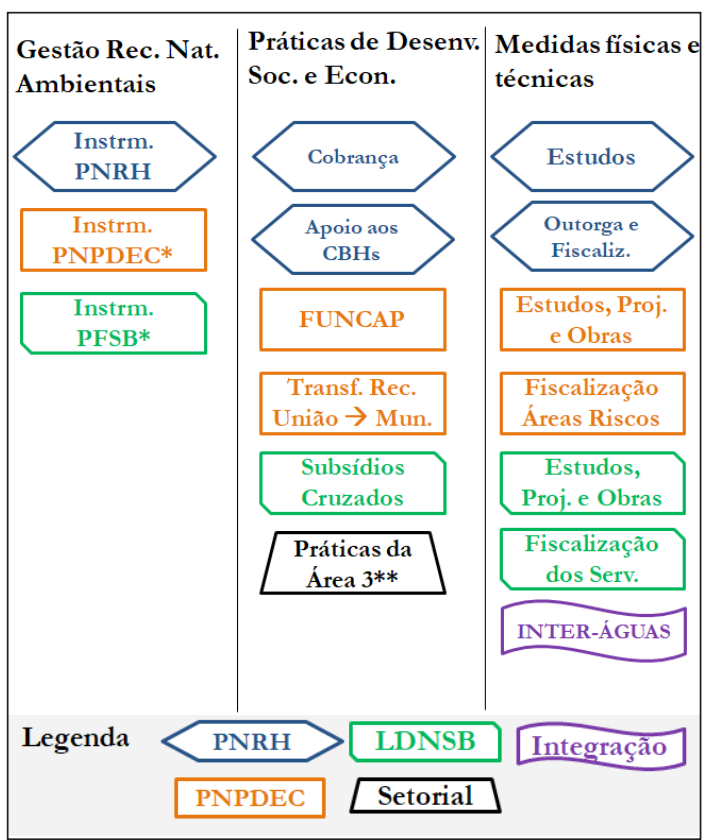

Figura 6 - Síntese das Interfaces para a Área Temática 4 - Aplicação e instrumentos na gestão de riscos. nejamento através dos planos de recursos hídricos, análise da viabilidade hídrica através das outorgas, CERTOH, e em grupos de trabalho especiais, no que caso de obras de grande impacto regional e interesse nacional, como é o caso do Projeto de Integração do Rio São Francisco.

Já os órgãos das Políticas de Defesa Civil e de Saneamento, mesmo que possam atuar diretamente na execução de obras de infraestrutura para atender seus interesses setoriais, pode existir potencial de sinergia de uma mesma obra para os dois setores.

A Figura 6 sintetiza as interfaces identificadas entre as Políticas para a Área Temática 4 e seus respectivos componentes: 1) Gestão de recursos naturais e ambientais; 2) Práticas de desenvolvimento social e econômico; e 3) Medidas físicas e técnicas.

\section{Área Temática 5 - Planos de contingência e gestão de emergências}

A Área 5 é abordada através de 2 componentes. $\mathrm{O}$ primeiro trata da preparação e planejamento de contingências. Para atender a este componente é necessária a existência de Planos de Contingência que abordem a questão da comunicação, coordenação, logística e a infraestrutura para preparaçáo e resposta. $\mathrm{O}$ segundo refere-se à gestáo de emergência e aborda a atuação na prática das organizaçóes na resposta a desastres (Tabela 6).

Nesta área temática a PNRH não apresenta interface, o que já foi identificado por Vendruscolo e Kobiyama (2007).

Conforme analisado na Área Temática 2, no que diz respeito ao Sistema de Alerta, o PSA consiste em uma ferramenta com forte potencial de interface com os Planos de Contingência a serem elaborados pelos Municípios, com apoio dos Estados, no âmbito da PNPDEC.

Isto porque o PSA aborda a gestão de riscos, com o foco no consumidor da água, que deve receber água segura e de qualidade e, assim, proteger sua saúde. Estabelece, ainda, planos de contingência para responder a falhas no sistema ou eventos imprevistos, que podem ter um impacto na qualidade da água, como as severas secas, fortes chuvas ou inundaçóes (MS/SVS, 2012) 
Tabela 6 - Interfaces entre a PNRH, PNPDEC e a LDNSB na Área Temática 4: Planos de contingência e gestão de emergências

\begin{tabular}{|c|c|c|c|}
\hline Componentes & PNRH & PNPDEC & LDNSB \\
\hline $\begin{array}{l}\text { Preparação e } \\
\text { planejamento de } \\
\text { contingências }\end{array}$ & - & $\begin{array}{l}\text { Planos de Contingência de Proteção e } \\
\text { Defesa Civil (Municípios elaboram com } \\
\text { apoio dos Estados). } \\
\text { Divulgação de protocolos de prevenção e } \\
\text { alerta e de ações emergenciais. }\end{array}$ & $\begin{array}{c}\text { Elaboração de PSA. } \\
\text { Notificações emitidas a } \\
\text { população pelo operador } \\
\text { quando houver situações } \\
\text { de emergência com } \\
\text { potencial para atingir a } \\
\text { segurança de pessoas e } \\
\text { bens. }\end{array}$ \\
\hline $\begin{array}{c}\text { Gestão de } \\
\text { emergências }\end{array}$ & - & $\begin{array}{l}\text { Prover solução de moradia temporária às } \\
\text { famílias atingidas por desastres. } \\
\text { Organizar e administrar abrigos } \\
\text { provisórios para assistência à população } \\
\text { em situação de desastre, em condições } \\
\text { adequadas de higiene e segurança. } \\
\text { Estimular a participação de entidades } \\
\text { privadas e da sociedade civil nas ações do } \\
\text { SINPDEC e promover o treinamento de } \\
\text { associações de voluntários para atuação } \\
\text { conjunta com as comunidades apoiadas. }\end{array}$ & $\begin{array}{c}\text { Interrupção do } \\
\text { Abastecimento. } \\
\text { Ações conforme } \\
\text { determinado junto ao PSA. }\end{array}$ \\
\hline
\end{tabular}

\section{CONCLUSÕES}

A articulação entre as políticas setoriais, o compartilhamento de funçóes entre as instituiçóes e a descentralização das açóes estão previstas legalmente nos diplomas legais das três políticas em análise (PNRH, PNPDEC e LDNSB/PFSB).

$\mathrm{O}$ processo de implementação de cada política apresenta similaridades e diferenças entre si, as quais são condicionadas pelo contexto histórico da sua implantação e do seu desenvolvimento.

Dentre as similaridades identificadas, nota-se a efetiva existência de planos e estudos setoriais para o desenvolvimento de objetivos comuns. Porém, para implementaçáo destes planos no contexto da intersetorialidade, é necessário o compartilhamento das agendas dos órgãos responsáveis pela implementação das políticas. No âmbito de tal compartilhamento de agendas, um exemplo de programa identificado consiste no INTERÁGUAS.

Contudo, com base no levantamento realizado pelo presente trabalho, conclui-se que de modo geral as açóes têm sido realizadas de modo mais fragmentadas entre os setores. Assim, mesmo que muitos dos objetivos possam ser comuns, as estratégias para atingi-los não são integradas. Tal situação inviabiliza, por exemplo, uma avaliação global da efetividade de açóes, em nível de governo para um dado objetivo (ex: garantir a segurança hídrica), uma vez que as açôes são dispersas entre diferentes políticas.

Dentre as particularidades em nível de estrutura institucional para cada política e que possuem influencia no contexto da intersetorialidade, destaca-se:

- PNRH: A descentralização em escala de organismos colegiados de bacia hidrográfica que envolvem a participaçáo da sociedade, fomentando a intersetorialidade no âmbito do Sistema de Recursos Hídricos.

- PNPDEC: A forte estruturação em nível municipal para a operacionalizaçáo da PNPDEC, o que se deve ao princípio da subsidiaridade. Contudo os Municípios são fortemente dependendes, em geral, de recursos financeiros, técnicos e operacionais dos Estados e da União.

- LDNSB: A relação entre o titular dos serviços e a concessionária em geral é confundida, pois há a tendência do titular delegar totalmente 
a responsabilidade pelos serviços prestados para a concessionária. Tal situaçáo dificulta a intersetorialidade devido à potencial falta de comprometimento político com a intersetorialidade, resultante dos conflitos setoriais internos existentes.

Cabe ressaltar que tanto a PNPDEC quanto a LDNSB reconhecem a importância da bacia hidrográfica como unidade de planejamento e gestão, porém, não consideram esse nível na espacialização nos respectivos Sistemas de Informação, por exemplo.

Nota-se que há um alto potencial de sinergia e integração entre as três políticas. Neste contexto, recomenda-se que seja realizado um cruzamento entre os Planos Setoriais já desenvolvidos nas diversas escalas, bem como os PPAs, para: i) a identificação das possibilidades de interfaces em nível de maior detalhe; ii) o estabelecimento de estudos específicos e os detalhamentos necessários em termos institucionais, organizacionais e fonte de recursos e iii) a definição de uma estratégia intersetorial, principalmente no que diz respeito a responsabilidades e prazos. Neste sentido também verifica-se a importância da realização de uma análise detalhada do porquê da fragmentação no que se refere às açóes de recursos hídricos e onde os gargalos institucionais se encontram.

\section{Referências}

ALMEIDA, P.E.G. A Política Nacional de Proteção e Defesa Civil: os desastres como problema político. In: $1^{\circ}$ SEMINÁRIO INTERNACIONAL DE CIÊNCIA POLÍTICA, 1, 2015, Porto Alegre. Anais... Porto Alegre: UFRGS, 2015. Disponivel em: https://www.ufrgs.br/sicp. Acesso em: 10. set. 2017.

ANA. Agência Nacional de Águas. Relatório Final do Plano Integrado de Recursos Hídricos da Unidade de Gestão de Recursos Hídricos Paranapanema - PIRH Paranapanema. Brasília, DF: Ministério do Meio Ambiente, 2016. Disponível em: http://paranapanema.org/file/pirh/PIRH_final.zip. Acesso em: 10. set. 2017.

ASSUMPCAO, R. F. et al . Possíveis contribuições da integração das políticas públicas brasileiras à redução de desastres. Saúde debate, Rio de Janeiro, v. 41, n. spe2, p. 39-49, Jun. 2017. Disponível em: http://www.scielo. br/scielo.php?script=sci_arttext\&pid=S0103-11042017000600039\&lng=en\&nrm=iso. Acesso em: 10 set. 2017.

BRASIL. Lei n 6.938 de 31 de agosto de 1981. Institui a Política Nacional de Meio Ambiente. Disponível em: http:// www.planalto.gov.br/ccivil_03/leis/L6938.htm. Acesso em: 10 set. 2017.

Constituição da República Federativa do Brasil de 1988. Disponível em: http://www.planalto.gov.br/ccivil_03/ constituicao/constituicaocompilado.htm. Acesso em: 10 set. 2017.

Decreto n 1.080, de 8 de março de 1994. Regulamenta o Fundo Especial para Calamidades Públicas (Funcap). Disponível em: http://www.planalto.gov.br/ccivil_03/decreto/1990-1994/D1080.htm. Acesso em: 10 set. 2017.

Lei no 9.433 de 8 de janeiro de 1997. Institui a Política Nacional de Recursos Hídricos. Disponível em: http:// www.planalto.gov.br/ccivil_03/leis/L9433.htm. Acesso em: 10 set. 2017.

Lei no 9.795, de 27 de abril de 1999. Institui a Política Nacional de Educação Ambiental. Disponível em: http://www.planalto.gov.br/ccivil_03/leis/L9795.htm. Acesso em: 10 set. 2017.

. Lei n $^{\circ} 10.257$ de 10 de julho de 2001. Estatuto da Cidade. Disponível em: http://www.planalto.gov.br/ccivil_03/ leis/LEIS_2001/L10257.htm. Acesso em: 10 set. 2017.

Lei no 11.107, de 6 de abril de 2005. Dispõe sobre normas gerais de contratação de consórcios públicos. Disponível em: http://www.planalto.gov.br/ccivil_03/_ato2004-2006/2005/lei//11107.htm. Acesso em: 10. set. 2017. 
. Decreto de 26 de setembro de 2005. Institui a Semana Nacional de Redução de Desastres. Disponível em: http://www.planalto.gov.br/ccivil_03/_Ato2004-2006/2005/Dnn/Dnn10640.htm. Acesso em: 10 set. 2017.

. Lei $n^{\circ} 11.445$ de 5 de janeiro de 2007. Estabelece as diretrizes nacionais para o saneamento básico e para a política federal de saneamento básico. Disponível em: http://www.planalto.gov.br/ccivil_03/_ato2007-2010/2007/ lei//11445.htm. Acesso em: 10 set. 2017.

. Decreto $n^{\circ} 6.666$, de 27 de novembro de 2008. Institui, no âmbito do Poder Executivo federal, a Infra-Estrutura Nacional de Dados Espaciais - INDE. Disponível em: http://www.planalto.gov.br/ccivil_03/_ato2007-2010/2008/ decreto/d6666.htm. Acesso em: 10. set. 2017.

Lei $n^{\circ} 12.340$, de $1^{\circ}$ de dezembro de 2010. Dispõe sobre as transferências de recursos da União aos órgãos e entidades dos Estados, Distrito Federal e Municípios para a execução de ações de prevenção em áreas de risco de desastres e de resposta e de recuperação em áreas atingidas por desastres e sobre o Fundo Nacional para Calamidades Públicas, Proteção e Defesa Civil. Disponível em: http://www.planalto.gov.br/ccivil_03/_ato20072010/2010/lei/l12340.htm. Acesso em: 10 set. 2017.

. Decreto $n^{\circ} 7.217$, de 21 de junho de 2010. Regulamenta a Lei no 11.445, de 5 de janeiro de 2007, que estabelece diretrizes nacionais para o saneamento básico. Disponível em: http://www.planalto.gov.br/ccivil_03/_ato20072010/2010/decreto/d7217.htm. Acesso em: 10 set. 2017.

2012a. Programa 2040 - Gestão de Riscos e Resposta a Desastres. Plano Plurianual 2012-2015. Anexo X - Programas Temáticos: Contextualização. Ministério da integração. Disponível em: http://www.mi.gov.br/c/document_library/get_file?uuid=e008bc1e-64bb-4eab-ac09-50451032c336\&groupld=10157... Acesso em: 10 set. 2017.

.2012b. Lei no 12.608 de 10 de abril de 2012. Institui a Política Nacional de Proteção e Defesa Civil. Disponível em: http://www.planalto.gov.br/ccivil_03/_ato2011-2014/2012/lei//12608.htm. Acesso em: 10 set. 2017.

. Plano Plurianual 2016-2019. Ministério do Planejamento, Desenvolvimento e Gestão, 2016. Disponível em: http://www.planejamento.gov.br/assuntos/planeja/plano-plurianual. Acesso em Acesso em: 10 set. 2017.

CESAN. Companhia Espírito Santense de Saneamento. Vazão média diária captada nos Rios Jucu e Santa Maria da Vitória. Disponível em: http://www.cesan.com.br/vazao-media-diaria-captada/. Acesso em Acesso em: 10 set. 2017.

COMITESINOS. Comitê de Gerenciamento da Bacia Hidrográfica do Rio dos Sinos. Níveis do Rio dos Sinos. Disponível em: https://docs.google.com/spreadsheets/d/1W-vvbKbQ_NPX-1ZG_3XAVGzvcL7KGyNyoNN8Hv2SF2U/ pub?gid=9\#. Acesso em: 10 set. 2017.

DRH/SEMA. Departamento de Recursos Hídricos da Secretaria Estadual de Meio Ambiente do Rio Grande do Sul. Relatório Final Síntese RFS Fase C - Plano de Bacia do Processo de Planejamento da Bacia Hidrográfica do Rio dos Sinos, Porto Alegre, RS: Governo do Estado do Rio Grande do Sul, 2014. Disponível em: http://www.comitesinos. com.br/wp-content/uploads/2014/11/SEMA_PRHC_SINOS_RFS.pdf Acesso em: 10 set. 2017.

EIRD/ONU. Secretaría Interinstitucional de la Estrategia Internacional para la Reducción de Desastres, Naciones Unidas. Vivir con el Riesgo Informe mundial sobre iniciativas para la reducción de desastres - Versión 2004, 2004. Disponível em: http://www.eird.org/vivir-con-el-riesgo/index2.htm. Acesso em: 10 set. 2017. 
FORGIARINI; F. R. F; SILVEIRAA. L. L.; SILVEIRA; G. L. Saneamento Básico e Recursos Hídricos: benefícios da interface das políticas de gestão In: SIMPÓSIO BRASILEIRO DE RECURSOS HÍDRICOS, 17., 2007, São Paulo. Anais... Porto Alegre: ABRH, 2007.

GARRIDO, J.R.S. Água, uma preocupação mundial. Revista CEJ. n. 12, p. 8-12, set./dez. 2000. Disponível em: http://www.cjf.jus.br/ojs2/index.php/revcej/article/viewArticle/351. Acesso em: 10 set. 2017.

GOERL, R.F.; KOBIYAMA, M.; PELLEIN, J.R.G.M.. Proposta metodológica para mapeamento de áreas de risco a inundação: Estudo de caso do município de Rio Negrinho - SC. Bol. geogr., Maringá, v. 30, n. 1, p. 81-100, 2012. Disponível em: http://www.periodicos.uem.br/ojs/index.php/BolGeogr/article/download/13519/9407 Acesso em: 10 set. 2017.

IPEA. Instituto de Pesquisa EcoPInômica Aplicada. O Papel dos Fundos Parafiscais no Fomento: FGTS e FAT. Brasília, DF: Ministério do Planejamento e Orçamento, 1997. Disponível em: http://www.ipea.gov.br/agencia/images/ stories/PDFs/TDs/td_0485.pdf. Acesso em: 10. set. 2017.

JIMENEZ-CISNEROS, B. Responding to the challenges of water security: the Eighth Phase of IHP, 2014-2021. Hydrological Sciences and Water Security: Past, Present and Future. Proceedings of the 11th Kovacs Colloquium, Paris, France, June 2014. IAHS Publ. 366, p.10-19, 2015.

MCIDADES. Ministério das Cidades. Portaria n² 21, de 22 de janeiro de 2014. Aprova o Manual de Instruções do Trabalho Social nos Programas e Ações do Ministério das Cidades. Disponível em: http://www.cidades.gov.br/images/ stories/ArquivosCidades/PAC/Manuais-Gerais-PAC/portaria21.pdf. Acesso em: 10. set. 2017.

MEIRELLES, H. L. Direito Municipal Brasileiro. 13. ed. São Paulo: Malheiros, 2003. p. 419.

MS. Ministério da Saúde. Portaria ${ }^{\circ} 2.914$, de 12 de dezembro de 2011. Dispõe sobre os procedimentos de controle e de vigilância da qualidade da água para consumo humano e seu padrão de potabilidade. Disponível em: http:// bvsms.saude.gov.br/bvs/saudelegis/gm/2011/prt2914_12_12_2011.html. Acesso em: 10. set. 2017.

MS/SVS. Ministério da Saúde. Secretaria de Vigilância em Saúde. Departamento de Vigilância em Saúde Ambiental e Saúde do Trabalhador. Plano de segurança da água: garantindo a qualidade e promovendo a saúde: um olhar do SUS. Brasília: Ministério da Saúde, 2012.

NASCIMENTO, S.. Reflexões sobre a intersetorialidade entre as políticas públicas. Serv. Soc. Soc., São Paulo , n. 101, p. 95-120, Mar. 2010. Disponível em: http://www.scielo.br/scielo.php?script=sci_arttext\&pid=S0101-66282010000100006\&lng=en\&nrm=iso. Acesso em: 10 set. 2017.

NOGUEIRA, F.; OLIVEIRA, V. E.; CANIL, K. Políticas públicas regionais para gestão de riscos: o processo de implementação no ABC, SP. Ambient. soc., São Paulo , v. 17, n. 4, p. 177-194, Dec. 2014. Disponível em: http://www. scielo.br/scielo.php?script=sci_arttext\&pid=S1414-753X2014000400010\&lng=en\&nrm=iso. Acesso em: 10 set. 2017.

OMS. Organização Mundial da Saúde. Planos de Segurança da Água. Disponível em: http://www.who.int/wsportal/ wsp/en. Acesso em: 10 set. 2017.

PNUD/SEDEC. Programa das Nações Unidas para o Desenvolvimento. Secretaria Nacional de Defesa Civil do Ministério da Integração Nacional. Projeto de Cooperação Técnica Internacional BRA/12/017 - Fortalecimento da 
Cultura de Gestão de Riscos de Desastres no Brasil. Brasília, Outubro de 2012. Disponível em: http://www.undp.org/ content/dam/undp/documents/projects/BRA/PRODOC\%20\%20Defesa\%20Civil_NEX.doc_Acesso em: 01 dez. 2017.

SALLES, M.J. Política Nacional de Saneamento: percorrendo caminhos em busca da universalização. 2009. 185 p. Tese (Doutorado em Ciências na área de Saúde Pública) - Escola Nacional de Saúde Pública Sergio Arouca, Rio de Janeiro, 2009. Disponível em: https://www.arca.fiocruz.br/bitstream/icict/2605/1/ENSP_Tese_Salles_Maria_Jos\%C3\%A9.pdf. Acesso em: 10 set. 2017.

SARAVANAN, V.S. A systems approach to unravel complex water management institutions, Ecological Complexity, Volume 5, Issue 3, 2008, Pages 202-215, ISSN 1476-945X, Disponível em: http://www.sciencedirect.com/science/ article/pii/S1476945X08000147. Acesso em: 10 set. 2017.

SAVENIJE, H. Panta Rhei, the new science decade of IAHS. Proceedings of the 11th Kovacs Colloquium, Paris, France, June 2014. IAHS Publ. 366, p. 20-22. 2015.

SNSA. Secretaria Nacional de Saneamento Ambiental. Plano Nacional de Saneamento Básico - PLANSAB. Brasília, DF: Ministério das Cidades, 2014. Disponível em: https://www.saneamentobasico.com.br/plano-nacional-de-saneamento-basico-plansab/ Acesso em: 10 set. 2017.

SPOSATI, A. Gestão pública intersetorial: sim ou não? Comentários de experiência. Serviço Social \& Sociedade, São Paulo, n. 85, p. 133-141, mar. 2006.

SRH/MMA. Secretaria de Recursos Hídricos. Ministério do Meio Ambiente. Plano Nacional de Recursos Hídricos. Brasília: DF, 2006. Disponível em: http://mma.gov.br/agua/recursos-hidricos/plano-nacional-de-recursos-hidricos. Acesso em: 10 set. 2017.

STF. Supremo Tribunal Federal. Ação Direta de Inconstitucionalidade 1.842 Rio de Janeiro. 2013a. Disponível em: http://www.stf.jus.br/portal/autenticacao/ sob o número 3815186. Acesso em: 10 set. 2017.

STF. Supremo Tribunal Federal. Ação Direta de Inconstitucionalidade 2.340 Santa Catarina. 2013b. Disponível em: http://www.stf.jus.br/portal/autenticacao/ sob o número 3483840. Acesso em: 10 set. 2017.

STF. Supremo Tribunal Federal. Medida Cautelar na Ação Direta de Inconstitucionalidade 2.077 Bahia. 2013c. Disponível em: http://www.stf.jus.br/portal/autenticacao/ sob o número 6884892. Acesso em: 10 set. 2017.

VENDRUSCOLO, S.; KOBIYAMA, M. Interfaces entre a Política Nacional de Recursos Hídricos e a Política Nacional de Defesa Civil, com relação aos desastres hidrológicos, no Brasil. In: Jornadas Internacionales sobre Gestión del Riesgo de Inundaciones y Deslizamientos de Laderas. São Carlos: USP/EESC/NIBH, Anais, 2007. 22p. CD-rom.

Vinicius Ferreira Dulac Universidade Federal do Rio Grande do Sul, Porto Alegre, RS, Brasil E-mail: vfdulac@gmail.com Contribuição do autor:

Pesquisa de campo; discussão dos dados e redação

Masato Kobiyama Universidade Federal do Rio Grande do Sul, Porto Alegre, RS, Brasil. E-mail: masato.kobiyama@ufrgs.br Contribuição do autor:

Indicação e seleção de fontes de dados; análises de dados e redação 